\title{
What should be done to develop ICT-based PE class in the era of the Fourth Industrial Revolution?: using AHP and IPA analysis within the Korean educational contexts
}

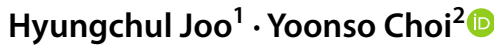

Received: 12 March 2021 / Revised: 20 July 2021 / Accepted: 26 July 2021 / Published online: 7 August 2021

(c) Education Research Institute, Seoul National University, Seoul, Korea 2021

\begin{abstract}
This study aims to explore educational and political efforts for PE teachers to implement ICT-based PE class by analyzing three significant phases (PE teacher, the curriculum, and teaching environment). To reach the goal of this study, we conducted AHP and IPA analysis to find out the priorities in order to implement ICT-based PE class. As a result, a total of 27 detailed contents were created by IPA analysis. Based on the IPA results, we interrogated what detailed contents should be firstly applied into actual PE practices by analyzing four dimensions by utilizing IPA. Based on the results, this study concluded with some significance, which are required to establish a better PE environment in the future society.
\end{abstract}

Keywords ICT class $\cdot$ Physical Education $\cdot$ AHP $\cdot$ IPA $\cdot$ Korean education policy

The popular Korean reality TV show Welcome, First Time in Korea?, which began airing on the Korean broadcasting channel MBC in July 2017 and is still showing, depicts foreigners traveling to Korea for the first time. On this program, foreign guests are shown to be surprised about the high level of ICT services in Korea. For example, virtual reality (VR), augmented reality (AR), mixed reality, holograms, and internet of things (IoT) technologies, which enable the five senses to experience the virtual world, are representative of Korean ICT. The rapid development of ICT in Korean society, as seen in reality shows, has led to changes in the educational environment as well. Many schools and institutions both in Korea and around the globe are seeking to create an efficient educational environment in physical education (PE) by shifting all classes to remote learning with the use of information technology following the onset of the COVID-19 crisis (Cutri \& Mena, 2020; Eder, 2020; Shettar et al., 2021).

Korea has responded to changes in society by utilizing its world-class ICT. The National Education Information

Yoonso Choi

yoonsochoi@gmail.com

1 Chung-Ang University, Seoul, South Korea

2 Sport and Health Science, Konkuk Univeristy, 268 Chungwondaero, Chungju-si 27478, Chungcheongbuk-do, Korea
System was implemented in the 1990s to improve the efficiency of education administration using online platforms. Detailed implementation strategies were also established to foster human resources, helping to bring about the Fourth Industrial Revolution, including a 100\% deployment of wireless infrastructure for elementary, middle, and high schools nationwide to foster future talent (Institute for Information \& Communication Technology Promotion, 2018.07.18). Since 2017, investment has been focused on practical education using ICT (space recognition-based AR technology and VRbased learning simulation technology), customized education (learning analysis technology, massive open online course data analysis technology, and social learning content technology), and IoT simulation education (coding education using smart toys equipped with electronic sensors).

The Korean government is encouraging the use of ICT in PE classes. Examples include initiatives organized by the Korean government departments Ministry of Culture, Sports and Tourism and the National Sports Promotion Corporation (Ministry of Culture, Sports \& Tourism, 2017). The government provides installation cost support for educational content, using VR sports gyms in elementary schools and maintenance services for one year from the date of installation and staff dispatch services for teachers who opt to use VR sports gyms for their PE classes. They thereby identify the potential for PE courses that are not usually offered at 
school, such as golf, hockey, rugby, skiing, snowboarding, and shooting (Seo et al., 2015).

The use of ICT to promote PE classes globally is under active discussion. Studies on this subject generally take the positive effects of using web-based technology into account (Lim et al., 2010; Ohuruogu et al., 2019) as an alternative to outdoor classes (sports film screenings, sports game analysis, UCC production, and so on), developing PE applications for high school (Kim \& Lyu, 2015), along with the possibility of using mobile devices to enhance the objectivity and transparency of performance assessment content and the methods of PE classes (Steinberg et al., 2020).

Some work has introduced the teaching experiences of PE teachers who utilize technology in their PE classes using smartphones, video-editing apps, motion analysis apps, spreadsheets, educational social networking methods, and so forth (Kim et al., 2017; Lee \& Jin, 2016). Furthermore, many PE classes have been introduced that use ICT and sensors to collect data on the amount of exercise a learner does and his or her performance, after which the collected data are analyzed to improve performance and athletic ability, including in the context of sports that require cooperation among learners, such as soccer, baseball, and basketball (Joo \& Choi, 2019; Park \& Yu, 2017; Park et al., 2018). Using ICT in PE classes presents a new form of teaching while providing the opportunity for learners to expand their cultural enjoyment in PE classes.

However, some results have shown that PE using ICT may not be efficient or effective (Villalba et al., 2017). In VR sports gyms operated by the government, the results have shown that educational performance has been minimal, in contrast to initial expectations (Joo \& Kim, 2018; You et al., 2019). The reason for this is that ICT utilization in the educational field was implemented by the government as a promotional strategy for strengthening public education and the growth of the education industry rather than being rooted in teacher demand (Kim et al., 2015; Noh et al., 2011). In other words, this can be interpreted as an appearance-oriented educational initiative by the government that does not involve consensus from teachers regarding ICT utilization at school, which could undermine the educational value of PE classes using ICT. Moreover, a wide range of technical equipment, such as WiFi, exercise sensors, high-speed cameras, and software for motion analysis, is required for the use of ICT in PE. For this reason, it is difficult for teachers to put ICT into operation in education (Joo \& Choi, 2019; Leam \& Ahn, 2014; Park et al., 2018).

In the era of rapid technological innovation, the demanded educational competency may change, and the next generation will require competitive skills for that future. South Korea has recognized the importance of ICT utilization and selected it for promotion as the country's major policy agenda following the emergence of the new high-tech-based paradigm. Korea is seeking to ensure that the benefits of ICT are consistent with the values and objectives of PE and to explore whether they can be carried out in actual education rather the passively acceptance of ICT itself in the educational field. To create this kind of educational environment, it is important to have a harmonious relationship in the form of a virtuous cycle among educational content, teaching methods, the school support system, teacher professionalism, and education policy suitable for PE classes. Previously, video clips have been regarded as only secondary material in PE teaching, but at present, un-tact learning is routine to ensure that students' health and safety in public education are maintained during the COVID-19 crisis (Putro et al., 2020) In addition, the government has announced new policies for Korean public education that state that AI and ICT should be supported as teaching tools through establishing un-tact learning-teaching platforms. This study examines what is needed for teachers, the curriculum, and the educational environment to implement ICT PE classes. In this way, we suggest directions that PE should pursue in an intelligent information society, as well as producing implications that will help support changes to current policies, which should consider different educational environments and limited resources.

\section{Research method}

\section{Literature review}

A literature review was conducted to establish key concepts, components, and directions for research using analytic hierarchy process (AHP) analysis. It was performed from March to June 2018. Academic papers, government policy reports, news articles, and literature cases were examined, and the results were used as basic data for an expert meeting as part of this study. Specifically, the following were examined: 1) educational support plans to improve PE teachers' ICT skills; 2) provision of experts for ICT-based PE class designs; 3 ) reduction of the workload of PE teachers; 4) active support from principals; 5) cooperation among PE teachers; and 6) changes to and requirements for education systems. By these means, objective information and data were collected, and meaningful research results were derived.

\section{Expert in-depth interviews and meetings}

In-depth interviews and consultations with experts were conducted from June to December 2018. A group of 12 experts, including seven teachers, three university professors, and two officials at the department of education, was convened. Individual interviews and group interviews were conducted after this. All interviews were conducted with the selected 
experts of the group. Each expert was interviewed twice for approximately $90 \mathrm{~min}$ per session. The group interview was conducted once using a semi-structured questionnaire. If problems of analysis and interpretation arose upon review of the interview, additional interviews were conducted by telephone or e-mail. To increase the reliability and validity of the data, the interviews were recorded, with the participants' consent, using a smartphone recorder, and the recorded files were transcribed to allow the participants to review them. All participants had experience using ICT in their PE classes and/or focused on studying ICT-based PE classes for years. Their information is summarized in Table 1.

Opinions were collected during the first individual interview analysis. The assessment goal was set as "improvements to ICT-based PE." Three categories were derived: teacher, curriculum, and environment. The second round of individual interviews was based on three assessment criteria that were derived from the first individual interviews. To derive feasible policies, some of the opinions presented in the first interviews were removed. The second round of individual interviews identified nine elements in the three main classifications. Based on these results, a total of 41 specific factors were derived. Finally, a group interview was conducted incorporating the results from the first and second individual rounds of interviews. For the group interview, content that overlapped with the second interview was integrated, and terms and specific cases were clarified. The discussion and consensus process were simplified into three main classifications, with nine elements and a total of 29 specific types of content. The final results are presented in Table 1.

\section{Building AHP indicators and analysis}

The AHP is an evaluation method that allows complex problems to be hierarchized, weighted, and prioritized to facilitate rational decision-making (Saaty, 1987). This study investigated what needs to be improved for actual ICT-based PE classes in schools. Basic data were derived to identify what should be improved in the field of PE so that schools can provide the education that learners need.

Following the literature review and expert meetings, the goal for AHP was set to "identify improvements for ICTbased PE classes." The main classifications were "teacher," "curriculum," and "environment." As shown in Table 1, the specific hierarchy for AHP evaluation was classified into three stages. The priorities were assessed through pairwise comparison between the main, elements, and small specific content.

In this study, 100 questionnaires were distributed to PE teachers for the AHP analysis. The survey was conducted from December 1 to December 23, 2019, among PE teachers teaching in Seoul and Gyeonggi Province. The sampling method involved snowball sampling begun with the participants in the expert meeting. Prior to the survey, all participants in the study were fully informed of its purpose. The AHP analysis was conducted after the participants were informed of the response method for a consistent pairwise comparison. All surveys were self-administered and returned by the participant. To improve the quality of responses, the researcher responded to questions on the questionnaire and explained the instrument until the participants fully understood it. Of the 100 copies, 76 were used as final data after 24 that contained inadequate answers or had a high consistency ratio (CR) were excluded.

Excel for Windows was used for AHP analysis to calculate the weights. The AHP analysis was performed in three stages. In step 1, CR values were analyzed to determine the logical consistency of the AHP responses. For consistency verification, $C R$ values were first analyzed for individual questionnaires that were returned. If $\mathrm{CR} \geq 0.1$, the response was judged to be consistent (Saaty, 1980). Step 2 derived the results of a pairwise comparison for each of the consistent individual questionnaires. Step 3 provided final verification
Table 1 Characteristics of participants

\begin{tabular}{lllllll}
\hline Division & Gender & Location & Career/year & Age & Final degree \\
\hline \multirow{2}{*}{ Teacher } & Public middle school & M & Gyeonggi-do & 11 & $40 \mathrm{~s}$ & Doctor \\
& & M & Daejeon & 7 & $30 \mathrm{~s}$ & Bachelor \\
& & F & Dae-gu & 14 & $40 \mathrm{~s}$ & Doctor \\
& Public high school & M & Dae-gu & 8 & $30 \mathrm{~s}$ & Bachelor \\
& & M & Daejeon & 8 & $30 \mathrm{~s}$ & Bachelor \\
& & Seoul & 21 & $50 \mathrm{~s}$ & Doctor \\
& & Gyeonggi-do & 20 & $40 \mathrm{~s}$ & Master \\
University professor & M & Gangwon & 10 & $40 \mathrm{~s}$ & Doctor \\
& & M & Gangwon & 7 & $50 \mathrm{~s}$ & Doctor \\
& M & Seoul & 6 & $30 \mathrm{~s}$ & Doctor \\
Official at the Department of Education & F & Seoul & 19 & $40 \mathrm{~s}$ & Bachelor \\
& M & Seoul & 23 & $50 \mathrm{~s}$ & Bachelor \\
\hline
\end{tabular}


by reviewing the $\mathrm{CR}$ of the complete data by integrating the results of the individual pairwise comparisons into geometric mean values.

\section{Importance-performance analysis}

Importance-performance analysis (IPA) provides useful information for determining areas, issues, policies, and so on that need to be addressed first in a given situation. IPA presents strategic alternatives and implications by interpreting the analytical results for each quadrant by conveying the results of the $\mathrm{Y}$-axis (importance) and $\mathrm{X}$-axis (performance) in four quadrants on a two-dimensional diagram (Martilla \& James, 1977; Matzler et al., 2004). The results in the first quadrant are set to "maintain status quo" because this area is defined by high importance and high performance. The results located in the second quadrant are set to "concentrate here" because they feature high importance but low performance. The results located in the third quadrant are categorized as "low priority" because they have both low importance and low performance. Finally, the fourth quadrant indicates items of low importance and high performance, expressed as "possible overkill." IPA is a useful tool for developing strategic policy, as it can identify rankings that should be focused on first, as well as areas of excess or drawbacks. Because IPA sets intersections based on the average value of each axis and gives meaning according to location, it has the advantage of easily and quickly producing results without requiring statistical techniques. In this study, the X-axis was set to "performance" for the IPA. In addition, the results calculated from the AHP analysis were applied to the Y-axis, marked "importance."

\section{Results}

The results of the AHP and IPA analyses follow. The results of the two sets of analyses look similar because both were undertaken to prioritize all of the specific factors (these are called distribution statuses in the IPA results). In general, AHP analysis focuses more on determining priorities linearly, and IPA analysis creates a matrix to clearly represent the gaps between importance and feasibility. For example, when a specific factor appears as the first priority in the AHP analysis, the order of the same factor in the IPA results may differ.

\section{Importance results derived from the AHP analysis}

To derive priorities for the items required for ICT PE classes, each weight was calculated for the main pasts, the elements, and specific contents. The weights for the main parts, elements, and specific contents were then multiplied to produce the total weight (TW). The TW results corresponding to the top $30 \%$ were as follows: willingness to challenge yourself (0.071), guarantee of autonomy (0.061), active school-level support policy (0.054), operation of the learning community (0.053), formation of consensus (0.050), support for assistant personnel (0.044), development of strategies to utilize ICT curriculum in a given class time (0.044), and the development of an ICT utilization strategy to achieve objectives (0.042). The specific AHP analysis results are given in Fig. 1.

\section{Feasibility results and IPA}

The mean values were calculated to determine the feasibility of the various items required for ICT PE classes. The IPA assigned eight items to Quadrant I, "Keep up the good work." Five items were included in Quadrant II, "Concentrate here." Eight items were included in Quadrant III, "Low priority," and six items were included in Quadrant IV, "Possible overkill." Fig. 1 shows the IPA results for the quadrants, and Table 2 provides a summary of the details.

\section{Discussion}

This study investigated the academic and political implications for future PE developments involving ICT by analyzing what efforts should be made in terms of teachers, curricula, and the environment in the new educational environment that ICT innovations will bring about. Below, we report the detailed implications of this study.

\section{Significance and suggestions for AHP analysis}

Prioritization was performed for a total of 27 items using AHP analysis. The implications will be suggested based on the top $30 \%$ because, among the 27 items presented, those in the top 30\% were relatively important for conducting ICT PE classes. Thus, detailed implications will be provided based on the main classifications and the eight categories that are in the top 30\% (Table 3).

First, the AHP analysis showed that the main category "teacher" included four items: "willingness to challenge yourself," "formation of consensus," "operation of learning community," and "support of assistant personnel." Thus, the willingness of PE teachers to challenge themselves, the formation of consensus, and cooperation among teachers are important for the extension of the use of ICT in PE classes. As mentioned noted in the introduction, ICT-related technologies are gradually altering educational concepts in Korean society. The government implemented a new curriculum in 2015 to create the education required by society, but teachers have criticized the changes because, while they 


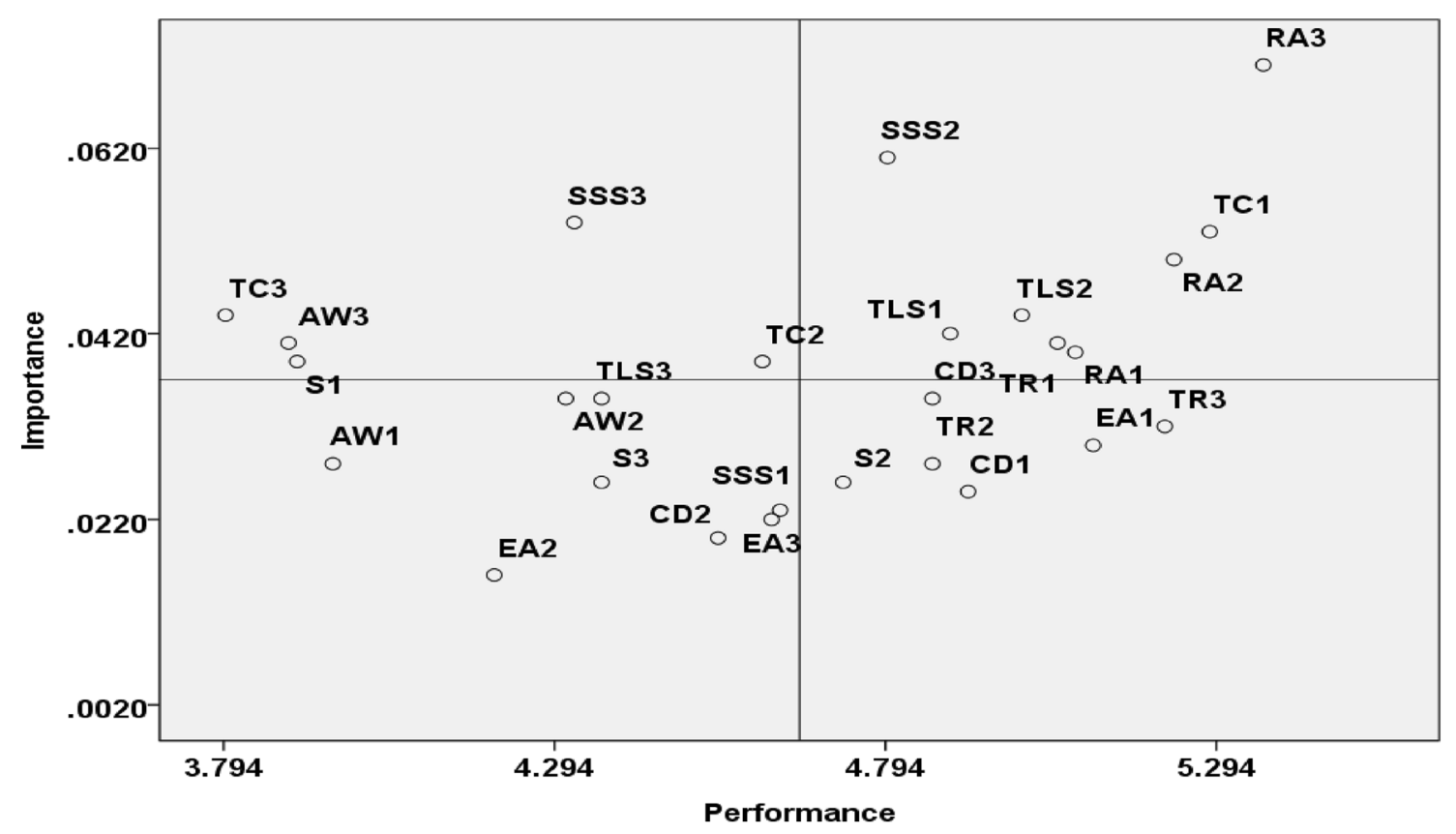

Fig. 1 IPA matrix result

are theoretical and fundamental, they are not practical (Song \& Choi, 2018). Thus, PE teachers are either not interested in new curricula or are preparing their educational activities passively (Jang, 2017; Kim \& You, 2010). Therefore, both the education system and the culture are necessary for the development of the curriculum and its application to educational sites based on PE teachers. For this, a learning community centered on PE teachers must be expanded to allow the curriculum to be developed by and to be feasible for PE teachers (Jang, 2017). For this change to take place in PE practices, teachers must reflect on themselves and change their perceptions of the use of ICT (Joo \& Choi, 2019; Zae $\&$ Youn, 2015). The willingness to challenge yourself was ranked highest in relation to this. In addition, priorities were included in the order in which consensus was reached by the professional learning community. The discussion on "support of assistant personnel" will be connected with the "environment," a result developed by AHP, which is discussed below.

Second, the AHP analysis showed that the main category "curriculum" included two items: "development of strategies to utilize ICT curriculum in a given class period" and "development of ICT utilization strategy to achieve objectives for each semester." For ICT PE classes to be involved in the educational field, a new culture must be established, where teachers can take the initiative in regard to the learning strategies in the curriculum. As noted, public education in Korea is centered on the government; therefore, the curriculum provided by the Ministry of Education is an important educational guideline. However, future education must be transformed into a role-centered school system in which school autonomy and school democracy are alive, one that allows teachers to have autonomy and self-determination. For this purpose, the practices of educationally advanced countries should be benchmarked. For example, all classes at Napa New-Technology High School, Desert Oasis High School, and Summit Public School are conducted based on project learning that combines two or more subjects. Under the autonomous direction of the teachers, a curriculum is implemented whereby students are allowed to conduct indepth learning as part of various teams. This type of school education was made possible with the support of schools, private foundations, and global corporations, such as the Bill and Melinda Gates Foundation. Investments are continuously being made in learning platforms and teachertraining programs using the latest advanced technologies, an orientation that facilitates the continuing development of new learning models. For novel educational experiments to take place in this way, a role-oriented school system must be established, in which teacher autonomy and self-determination are empowered by ensuring teacher autonomy and active support at the school level. More specific discussions on these results should be linked to the results relating to "environment," discussed below.

Third, the AHP analysis showed that the main category, "environment," included two items: "guarantee of teachers' autonomy" and "active school-level support policy." Recently, the Ministry of Education announced its college admission policy of "extending the College Scholastic Ability Test by $40 \%$ or more." As shown in the college entrance 
Table 2 AHP analysis results

\begin{tabular}{|c|c|c|c|c|c|c|c|c|c|}
\hline \multirow{2}{*}{\multicolumn{2}{|c|}{$\frac{\text { Main category }}{\text { Factor }(\text { C.I. }=0.001)}$}} & \multicolumn{3}{|l|}{ Intermediate category } & \multicolumn{3}{|l|}{ Small category } & \multicolumn{2}{|l|}{ Importance } \\
\hline & & Factor & C.I & Weight & Factor & C.I & Weight & Total weight & Rank \\
\hline \multirow[t]{9}{*}{ Teacher } & 0.401 & Raising awareness (RA) & 0.001 & 0.401 & Reflective thinking (RA1) & 002 & 0.250 & 0.040 & 11 \\
\hline & & & & & Formation of consensus (RA2) & & 0.311 & 0.050 & 5 \\
\hline & & & & & $\begin{array}{l}\text { Willingness to challenge your- } \\
\text { self (RA3) }\end{array}$ & & 0.440 & 0.071 & 1 \\
\hline & & Teacher cooperation (TC) & & 0.339 & $\begin{array}{l}\text { Operation of learning commu- } \\
\text { nity (TC1) }\end{array}$ & 0.001 & 0.387 & 0.053 & 4 \\
\hline & & & & & $\begin{array}{l}\text { Building teacher network among } \\
\text { local schools (TC2) }\end{array}$ & & 0.286 & 0.039 & 12 \\
\hline & & & & & $\begin{array}{l}\text { Support of assistant personnel } \\
\text { (TC3) }\end{array}$ & & 0.327 & 0.044 & 6 \\
\hline & & Administrative work (AW) & & 0.260 & Securing research time (AW1) & 0.001 & 0.268 & 0.028 & 19 \\
\hline & & & & & $\begin{array}{l}\text { Simplification of administrative } \\
\text { procedure (AW2) }\end{array}$ & & 0.334 & 0.035 & 14 \\
\hline & & & & & Reducing workload (AW3) & & 0.398 & 0.041 & 9 \\
\hline \multirow[t]{9}{*}{ Curriculum } & 0.269 & Curriculum development (CD) & 0.005 & 0.299 & $\begin{array}{l}\text { Developing ICT-based curricu- } \\
\text { lum (CD1) }\end{array}$ & 0.001 & 0.313 & 0.025 & 23 \\
\hline & & & & & $\begin{array}{l}\text { Developing ICT-based cur- } \\
\text { riculum that meets national } \\
\text { requirements }(\mathrm{CD} 2)\end{array}$ & & 0.253 & 0.020 & 26 \\
\hline & & & & & $\begin{array}{l}\text { Developing ICT-based curricu- } \\
\text { lum for classroom PE (CD3) }\end{array}$ & & 0.434 & 0.035 & 15 \\
\hline & & $\begin{array}{l}\text { Teaching-learning strategy } \\
\text { (TLS) }\end{array}$ & & 0.447 & $\begin{array}{l}\text { Development of ICT utilization } \\
\text { strategy to achieve objectives } \\
\text { per semester (TLS1) }\end{array}$ & 0.004 & 0.347 & 0.042 & 8 \\
\hline & & & & & $\begin{array}{l}\text { Development of strategies to } \\
\text { utilize ICT curriculum in a } \\
\text { given class time (TLS2) }\end{array}$ & & 0.364 & 0.044 & 7 \\
\hline & & & & & $\begin{array}{l}\text { Development of safety manual } \\
\text { (TLS3) }\end{array}$ & & 0.289 & 0.035 & 16 \\
\hline & & Educational assessment (EA) & & 0.254 & $\begin{array}{l}\text { Evaluation of learning achieve- } \\
\text { ment in ICT-based PE class } \\
\text { (EA1) }\end{array}$ & 0.001 & 0.440 & 0.030 & 18 \\
\hline & & & & & $\begin{array}{l}\text { Evaluation of teaching methods } \\
\text { through peer reviews (EA2) }\end{array}$ & & 0.232 & 0.016 & 27 \\
\hline & & & & & $\begin{array}{l}\text { Evaluation of learning environ- } \\
\text { ment for ICT-based PE (EA3) }\end{array}$ & & 0.328 & 0.022 & 25 \\
\hline \multirow[t]{9}{*}{ Environment } & 0.330 & System (S) & 0.001 & 0.274 & $\begin{array}{l}\text { Hardware and software support } \\
\text { (S1) }\end{array}$ & 0.002 & 0.427 & 0.039 & 13 \\
\hline & & & & & $\begin{array}{l}\text { Operating a pilot school using } \\
\text { ICT (S2) }\end{array}$ & & 0.286 & 0.026 & 21 \\
\hline & & & & & $\begin{array}{l}\text { Legal deregulation and support } \\
\text { of activity manuals (S3) }\end{array}$ & & 0.287 & 0.026 & 22 \\
\hline & & Teacher re-education (TR) & & 0.307 & $\begin{array}{l}\text { Case-driven hands-on work- } \\
\text { shops (TR1) }\end{array}$ & 0.001 & 0.408 & 0.041 & 10 \\
\hline & & & & & $\begin{array}{l}\text { Professional consulting support } \\
\text { (TR2) }\end{array}$ & & 0.273 & 0.028 & 20 \\
\hline & & & & & $\begin{array}{l}\text { Sharing best practices and ICT } \\
\text { application programs (TR3) }\end{array}$ & & 0.319 & 0.032 & 17 \\
\hline & & School support system (SSS) & & 0.419 & $\begin{array}{l}\text { School principal's strong desire } \\
\text { and goodwill (SSS1) }\end{array}$ & 0.001 & 0.166 & 0.023 & 24 \\
\hline & & & & & $\begin{array}{l}\text { Ensuring the autonomy of teach- } \\
\text { ers (SSS2) }\end{array}$ & & 0.444 & 0.061 & 2 \\
\hline & & & & & $\begin{array}{l}\text { Active school-level support } \\
\text { policy (SSS3) }\end{array}$ & & 0.390 & 0.054 & 3 \\
\hline
\end{tabular}


Table 3 AHP indicators for using ICT in PE class

\begin{tabular}{|c|c|c|}
\hline Criteria & Elements & Content \\
\hline \multirow[t]{9}{*}{ Teacher } & \multirow[t]{3}{*}{ Raising awareness } & Willingness to improve classes through self-reflection \\
\hline & & PE teachers' consensus on ICT utilization \\
\hline & & Willingness to challenge yourself with new teaching-learning methods of ICT utilization \\
\hline & \multirow[t]{3}{*}{ Teacher cooperation } & $\begin{array}{l}\text { Operation of a professional learning community to address differences in ICT utilization among } \\
\text { school teachers }\end{array}$ \\
\hline & & $\begin{array}{l}\text { Building a teaching-learning development community through a network of teachers among local } \\
\text { schools }\end{array}$ \\
\hline & & $\begin{array}{l}\text { Expanding support for assistant personnel to promote ICT PE classes (intern teachers, sports instruc- } \\
\text { tors, PE teachers, and so forth) }\end{array}$ \\
\hline & \multirow[t]{3}{*}{ Administrative work } & Securing research time for teaching-learning methods using ICT \\
\hline & & Simplifying administrative procedures required to develop ICT PE classes \\
\hline & & $\begin{array}{l}\text { Building a jobs system to alleviate the administrative workload of PE teachers (e.g., having teachers } \\
\text { or teams dedicated to administrative affairs only and so forth) }\end{array}$ \\
\hline \multirow[t]{9}{*}{ Curriculum } & \multirow[t]{3}{*}{ Curriculum development } & Development of ICT-based PE and curriculum focused on learners \\
\hline & & Development of ICT-based PE and curriculum for realization of the educational value of government \\
\hline & & Development of ICT PE curriculum as part of classroom sports course \\
\hline & \multirow[t]{3}{*}{ Teaching-learning strategy } & $\begin{array}{l}\text { Development of ICT utilization strategies to achieve the goals of all units for the first semester } \\
\text { (developing ICT-based teaching-learning strategies suitable for achieving the final learning goals } \\
\text { of the PE curriculum) }\end{array}$ \\
\hline & & Development of teaching and learning strategies to use ICT efficiently in a set class time \\
\hline & & $\begin{array}{l}\text { Development of a manual for sudden situations and accidents that can occur during the operation of } \\
\text { an ICT-based curriculum }\end{array}$ \\
\hline & \multirow[t]{3}{*}{ Educational assessment } & Evaluation of learning achievement in an ICT-based PE class \\
\hline & & Evaluation of teaching methods through peer reviews \\
\hline & & Evaluation of the learning environment for ICT-based PE \\
\hline \multirow[t]{9}{*}{ Environment } & \multirow[t]{3}{*}{ System } & $\begin{array}{l}\text { ICT hardware (WiFi, sensor devices, and so forth) for PE and software and financial systematic sup- } \\
\text { port }\end{array}$ \\
\hline & & Operating a pilot school for PE using ICT \\
\hline & & $\begin{array}{l}\text { Legal deregulation and specific activity guidelines for activating new educational initiatives (example } \\
\text { of an online one-person creator: Sect. } 64 \text { of the National Public Officials Act [No profit-making or } \\
\text { double dipping]: Civil servants are not allowed to work for profit other than official duties and are } \\
\text { not allowed to perform other duties without permission from the head of their agency) }\end{array}$ \\
\hline & \multirow[t]{3}{*}{ Teacher re-education } & $\begin{array}{l}\text { Case-driven hands-on workshop for enhanced professionalism of PE teachers regarding ICT utiliza- } \\
\text { tion methods }\end{array}$ \\
\hline & & Specialized consulting support for ICT PE classes and overall operation \\
\hline & & Development of a program-sharing system and best practices \\
\hline & \multirow[t]{3}{*}{ School support system } & The school principal's strong desire and goodwill toward ICT-enabled PE \\
\hline & & $\begin{array}{l}\text { Ensuring the autonomy of PE teachers on the level of schools for the development of new PE classes } \\
\text { and educational initiatives }\end{array}$ \\
\hline & & $\begin{array}{l}\text { Active support, encouragement, and financial support at the school level, even if initial trial and error } \\
\text { occurs }\end{array}$ \\
\hline
\end{tabular}

requirement policy, Korea's education policy has not freed itself from under the state-run education administration system. With changes of government, the administrations have ostensibly advocated "authorization" and "self-regulation," "innovation schools," and "self-directed learning" to leave behind the state-run educational administration system, but there has as yet been no fundamental change (Joo \& Choi, 2019; Lee, 2011). Furthermore, laws related to the duties of PE teachers show that they are being overworked. The duties and roles of teachers as specified in the Basic
Education Law, the Elementary and Secondary Education Act and Enforcement Decree, and the National Civil Service Act are related to general teaching duties, including teaching classes, providing student-support services, implementing behavioral guidance, and guiding after-school activities. In addition, under the School Sports Promotion Act, PE teachers are required to manage sports club activities, health maintenance classes, after-school classes, physical activity promotion system activities, and student athletics. It seems clear that PE teachers have been given an excessive 
workload. Several studies have already noted that these areas present the biggest obstacles to advancement in education (Joo \& Kim, 2018; Kang, 2019; Lee, 2011, 2019). In other words, excessive accountability and bureaucratic control of teachers can hinder teacher autonomy and free growth. In addition, teachers exacerbate lethargy, unprofessionalism, and deskilling in their educational activities and education curriculum development (Apple \& Jungck, 1990; Lee et al., 2019). Therefore, an educational ecosystem should be developed that can enhance teachers' professionalism and resilience. The results of this study show that we need to create an organizational atmosphere that ensures autonomy for PE teachers. When trial and error occur in the early stages as teachers undertake new educational experiments, active support, encouragement, and financial support at the school level will be important. In particular, expanding personnel support for intern teachers, sports instructors, and PE teachers may be a solution to the problem, allowing more professional educational activities to be planned that will not require excessive responsibility.

In conclusion, the following endeavors are required to attain high-quality PE classes using ICT. First, it is necessary to provide information to and training opportunities for $\mathrm{PE}$ teachers as they undertake new educational approaches. Second, support and expansion systems should be established to allow new directions to be implemented across schools. Third, an incentive system should be established for PE teachers to engage in attempts at new educational approaches, which would also be linked to teachers' excessive workload. Fourth, the Ministry of Education, the Board of Education, and local schools should develop a horizontal system rather than a vertical one.

\section{Significance of the IPA results}

According to the results provided by IPA in this study, the first quadrant to be improved is Quadrant II. This is because that area includes factors that respondents perceive as important but low in feasibility. Therefore, this chapter focuses on the results of Quadrant II and presents comprehensive implications for the remaining quadrants. In addition, as with the results of the AHP analysis, IPA was used to provide comprehensive implications that take into account the highly interrelated nature of the derived results (Table 4).

First, IPA showed five items that needed improvement in Quadrant II. As shown in Table 2, the most important areas to improve for PE teachers were related to the ideas of the "teacher" and the "environment" in the main categories. Specifically, these items were "building a network of teachers among local schools," "support for assistant personnel," "reducing the workload," "hardware and software support," and "active support policies at the school level."
To achieve the educational values required by the national standard PE curriculum at the level of individual teachers, many teachers also adopt ICT. Specifically, they manage their PE classes to improve the healthcare, physical training, game performance, and physical expression skills required by the state by utilizing mobile platforms, motion analysis apps, cloud computing, and QR codes (Joo \& Choi, 2019; Moon, 2017; You et al., 2019). Nevertheless, the poor facilities and lack of educational equipment in schools make it difficult to properly utilize the advantages of ICT for educational practices (Lee \& Jung, 2017). In addition, many PE teachers have difficulty in developing new content because they are also responsible for a variety of tasks, in addition to class activities (Kang, 2019; Lee, 2019). In this regard, a job environment and atmosphere should be created in which new educational attempts can be made, along with establishing a system of division of tasks that can alleviate teachers' duties at the school level. To this end, active interactions with fellow teachers at a school should be simplified, and further exchanges in learning, discussion, and educational content should be made through links with teachers working at neighboring schools. Therefore, it is necessary to expand the division of the administrative system and support for assistant personnel to alleviate the duties of PE teachers at the school level.

Meanwhile, at the level of the government, the Ministry of Culture, Sports and Tourism and the National Sports Promotion Corporation have been pursuing policies to distribute VR sports gyms to elementary schools nationwide since 2017 to encourage ICT-based PE classes. Despite this massive governmental support, the effectiveness of this program has been lacking. Many have reported being unable to concentrate on essential educational activities due to system errors during the brief 45-min PE class (Joo \& Kim, 2018; You et al., 2019). To compensate for this, the state has provided support for staff dispatch and the maintenance of sports gyms, but no fundamental solution to the problem of system stability is provided (Joo \& Kim, 2018). From this point of view, ICT utilization should not simply take advantage of advanced technology but should also seek to improve the quality of PE (Casey et al., 2017; Lee, 2019). For this to be effective, it is necessary to identify the pros and cons of the VR sports gyms that are being installed through continuous communication among PE teachers, government ministries, and developers to track their progress and amend their limitations. Furthermore, it is necessary to increase understanding of and interest in the education policies that are being implemented at the national level through the establishment of a network among PE teachers at schools currently in operation and PE teachers at schools near the area. On this basis, we must increase the capacity and awareness of PE teachers as they use ICT in their PE classes. The job system should be improved for PE teachers to focus more 
Table 4 IPA indicators for using ICT in PE class

\begin{tabular}{|c|c|c|c|c|c|}
\hline Criteria & & TW rank & Distribution status & Importance & Feasibility \\
\hline \multirow[t]{8}{*}{ Quadrant I } & \multirow[t]{8}{*}{ Status quo (Importance $\uparrow \&$ Feasibility $\uparrow$ ) } & 11 & Reflective thinking (RA1) & 0.040 & 5.08 \\
\hline & & 5 & Formation of consensus (RA2) & 0.050 & 5.23 \\
\hline & & 1 & Willingness to challenge yourself (RA3) & 0.071 & 5.37 \\
\hline & & 4 & Operation of learning community (TC1) & 0.053 & 5.28 \\
\hline & & 2 & Guaranteeing teachers' autonomy (SSS2) & 0.061 & 4.80 \\
\hline & & 8 & $\begin{array}{l}\text { Development of ICT utilization strategy to } \\
\text { achieve objectives per semester (TLS1) }\end{array}$ & 0.042 & 4.89 \\
\hline & & 7 & $\begin{array}{l}\text { Development of strategies to utilize ICT cur- } \\
\text { riculum in a given class time (TLS2) }\end{array}$ & 0.044 & 5.00 \\
\hline & & 10 & Case-driven hands-on workshops (TR1) & 0.041 & 5.05 \\
\hline \multirow[t]{5}{*}{ Quadrant II } & \multirow[t]{5}{*}{$\begin{array}{l}\text { Focused improvement (Importance } \uparrow \& \\
\text { Feasibility } \downarrow \text { ) }\end{array}$} & 12 & $\begin{array}{l}\text { Building teacher network among local } \\
\text { schools (TC2) }\end{array}$ & 0.039 & 4.61 \\
\hline & & 6 & Support for assistant personnel (TC3) & 0.044 & 3.80 \\
\hline & & 9 & Reducing workload (AW3) & 0.041 & 3.89 \\
\hline & & 13 & Hardware and software support (S1) & 0.039 & 3.91 \\
\hline & & 3 & Active school-level support policy (SSS3) & 0.054 & 4.32 \\
\hline \multirow[t]{8}{*}{ Quadrant III } & \multirow[t]{8}{*}{ Inferior rank (Importance $\downarrow \&$ Feasibility $\downarrow$ ) } & 19 & Securing research time (AW1) & 0.028 & 3.96 \\
\hline & & 14 & $\begin{array}{l}\text { Simplification of administrative procedure } \\
\text { (AW2) }\end{array}$ & 0.035 & 4.31 \\
\hline & & 26 & $\begin{array}{l}\text { Developing ICT-based curriculum that meets } \\
\text { national requirements (CD2) }\end{array}$ & 0.020 & 4.54 \\
\hline & & 16 & Development of safety manual (TLS3) & 0.035 & 4.37 \\
\hline & & 27 & $\begin{array}{l}\text { Evaluation of teaching methods through peer } \\
\text { reviews (EA2) }\end{array}$ & 0.016 & 4.20 \\
\hline & & 25 & $\begin{array}{l}\text { Evaluation of learning environment for ICT- } \\
\text { based PE (EA3) }\end{array}$ & 0.022 & 4.62 \\
\hline & & 22 & $\begin{array}{l}\text { Legal deregulation and support of activity } \\
\text { manuals (S3) }\end{array}$ & 0.026 & 4.37 \\
\hline & & 24 & $\begin{array}{l}\text { School principal's strong desire and goodwill } \\
\text { (SSS1) }\end{array}$ & 0.023 & 4.64 \\
\hline \multirow[t]{6}{*}{ Quadrant IV } & \multirow{6}{*}{$\begin{array}{l}\text { Avoid overworking (Importance } \downarrow \& \text { Feasibil- } \\
\text { ity } \uparrow \text { ) }\end{array}$} & 23 & Developing ICT-based curriculum (CD1) & 0.025 & 4.92 \\
\hline & & 15 & $\begin{array}{l}\text { Developing ICT-based curriculum for class- } \\
\text { room PE (CD3) }\end{array}$ & 0.035 & 4.87 \\
\hline & & 18 & $\begin{array}{l}\text { Evaluation of learning achievement in ICT- } \\
\text { based PE class (EA1) }\end{array}$ & 0.030 & 5.11 \\
\hline & & 21 & Operating a pilot school using ICT (S2) & 0.026 & 4.73 \\
\hline & & 20 & Professional consulting support (TR2) & 0.028 & 4.87 \\
\hline & & 17 & $\begin{array}{l}\text { Sharing best practices and ICT application } \\
\text { programs (TR3) }\end{array}$ & 0.032 & 5.22 \\
\hline
\end{tabular}

on their educational activities. To do this, an expansion of assistant personnel could be implemented. In addition, the hardware and software should be supported to facilitate ICT utilization in PE classes. Developing educational hardware and software for PE classes will have to be supported at the local school level, in that it is costly and time-consuming. Moreover, by establishing a network of teachers among local schools, PE teachers need to develop an understanding of and consensus on how to utilize ICT tools that are being put to work at the national level. This will require a drastic overhaul of the administrative system, which has been practiced in a customary manner, and ICT utilization methods need to be continuously developed for use in PE.

Second, the IPA showed eight items in Quadrant I for which the status quo should be maintained. Specifically, these were the following: "reflective thinking," "forming consensus," "willingness to challenge yourself," "operating a learning community," "guarantee of teachers' autonomy," "development of ICT utilization strategy to achieve objectives per semester," "development of strategies to utilize ICT curriculum in a given class period," and "case-oriented hands-on workshops." The commonalities in these factors 
presented in Quadrant I can be summarized by a reflection and implementation process to explore new PE models using ICT. Sky Castle, a popular 2019 JTBC drama, is an example of the adverse effects of meritocracy supported by functionalist educational sociology, pointing to the problems of the CSAT-centric education system. In addition, Black Dog, a tvN drama that aired in January 2020, diagnosed various inconvenient truths found at schools, looking at problems from the perspective of a non-tenure track teacher. One common problem seen in both dramas was the role and autonomy of teachers in schools and the development of a consensus with the viewers. In other words, the willingness and awareness of PE teachers to use ICT in PE classes is essential, given that the quality of school education depends on teachers. Specifically, self-reflection on one's classes, consensus formation on ICT usability within PE classes, and the willingness to challenge yourself should be continuously maintained. In addition, specific strategies for the educational use of ICT are needed. Further, national guidelines cannot be ignored within Korean society, which emphasizes public education. Therefore, it is necessary to consider how to use ICT to achieve semester goals and develop strategies for teaching and learning that can be implemented efficiently within a set class time. In this regard, the autonomy of PE teachers at the school level should be guaranteed, and caseoriented hands-on workshops must be provided. In addition, a professional learning community should be developed to address differences in ICT utilization capabilities among teachers.

Third, Quadrant III, a low-ranking area factor in terms of both importance and feasibility, had eight items, and Quadrant IV, an area with low importance but high feasibility, had six items. Quadrants III and IV are areas that should be strategically or partially improved; thus, implications will be suggested for selecting items. In this regard, the simplification of administrative procedures in relation to administrative work in Quadrant III should be selectively enhanced. At present, general administrative work in the educational field utilizes the NICE system, and administrative handling of financial affairs, such as budgeting and accounting, utilizes the K-Edu-fine school accounting system. These e-payment systems have the advantage of enabling transparent school administration, but they have the disadvantage of increasing teacher workload and the complexity of system operation. Teachers continue to complain the difficulties due to the complexity of the budget procedures, the difficulty of the accounting terms, and the unclarity of the menu composition in the system, especially with regard to the Edu-fine system (Kang, 2013; Lee, 2016). In addition, Jang and Lee (2017) indicate the problem of administrative procedures that are not distributed in proportion to the workload and intensity of individual teachers in relation to allocating administrative work that is being done outside of teachers' educational activities. In this regard, PE teachers also argue that decision-making processes within the school organization should be consistent and unbiased, and the rigid school administrative system should be changed (Lee, 2019; Lee \& Jun, 2014). For educational experiments using ICT to be carried out smoothly by PE teachers, administration and budgeting procedures must be simplified and made fairer. In particular, the overall improvement of school administration procedures should be strategically implemented, given that utilizing ICT in PE classes requires extracurricular teaching aids.

In Quadrant IV, ICT PE curriculum development should be selectively enhanced as part of indoor PE, such as classrooms and small spaces. The purpose of utilizing ICT technology for education is to increase the efficiency of education by moving from offline to online. The development of advanced ICT has shown the potential for personalized services, particularly healthcare services, administered using smartwatches, IBM Watson (artificial intelligence doctors), and smart hospitals. In addition, ICT development has provided an opportunity for new educational experiments. Increased interaction among learners, educational activities using collective intelligence, and the provision of personalized educational content are typical examples (Joo \& Kim, 2018). The keywords to be noted here are "interaction," "personalized service," and "collective intelligence." Existing PE classes are taught in person, with the teacher at the center. The problem, however, was that learners participated only in passively manner or avoided classes (Kim, 2014). Therefore, it is necessary to utilize ICT's interactivity, personalized service, and collective intelligence in PE classes. In other words, if there is a class that collects exercise data through practical classes and analyzes exercise moves, activity radius, and organizational tactics with both the teacher and learner participating, more effective classes will be possible, and education can be customized to the learners will be possible. To establish this education system, the development of a systematic curriculum for PE teachers is necessary, and this needs to be gradually improved, as the ability to take advantage of the benefits of ICTs is necessary.

\section{Conclusion}

The new paradigm implemented by the Fourth Industrial Revolution is leading to a transformation by fostering new values. Changes to the public education system for the next generation in preparation for rapid technological changes constitute a highly important topic worldwide, including in Korean society. In particular, PE classes that advocate knowledge, virtue, and the body also require the creation of a new educational method amid this trend of change. In other words, in-depth consideration is required concerning the direction in which PE should move, in line with 
the pace of technological change. This study explored the critical factors required for ICT-enabled PE classes to be established at educational sites. Specifically, the importance of factors was identified through AHP, and the IPA of the derived importance results and feasibility in the field was used to provide practical and academic implications. To create better PE classes in a new educational environment, in which e-learning systems have expanded following the emergence of the COVID-19 crisis, PE teachers must plan classes while keeping various complex factors in mind. To do so, cooperation is required among various stakeholders, including schools, the government, and academia. Taking this approach, we hope that PE classes that fit the original purpose of education can be carried out and that teachers can carry out the type of PE classes to prepare students for the future. In addition, although this study was conducted in the educational environment of Korea, it may make its largest academic contribution by providing a systematic analysis of what should be involved in PE classes. In particular, the rapid development of technologies in Korean society has led to changes in the educational environment as well, but $P E$ teachers have struggled with inefficiency in educational policies related to the practical utilization of ICT in their classes. As shown in this study, both hardware (facilities, space, tools, guidelines, administration, etc.) and software (ICT-based curricula, teacher competency, policies, etc.) aspects should be supported simultaneously to manage ICT-based PE classes efficiently. Following the onset of the COVID-19 crisis, most countries have had no choice but to shift their educational environment to a completely remotelearning approach. It is hoped that this study will contribute to the development of PE in Korea and provide basic data for both Asian and Western countries as they face educational situations similar to those posed in Korea.

Finally, we provide comments on the limitations of this study and its significance from its results and conclusions. First, this study presented 27 factors for utilizing ICT in PE classes and suggested implications through AHP and IPA. However, the priorities of the 27 factors presented in this study were not absolute. This study was conducted in relation to the educational situation in Korea, and the state and environment of each school differ from all others. Thus, no study can be considered to be an absolute standard. However, it is significant that the findings developed here related to PE teachers specializing in the use of ICT. Second, the ICT factors obtained in this study were somewhat extensive. PE teachers use different ICTs to their classes than other teachers do, and different PE teachers' ICTs differ from each other as well. Thus, it was difficult to decide which ICTs to set as a standard. Although the standards for ICTs are noted in this study, more meaningful results may form a follow-up study that could be centered on specific utilization cases in PE classes using ICT.

\section{References}

Apple, M., \& Jungck, S. (1990). You don't have to be a teacher to teach this unit: Teaching, technology, and gender in classroom. American Educational Research Journal, 27(2), 227-251.

Casey, A., Goodyear, V. A., \& Armour, K. M. (2017). Rethinking the relationship between pedagogy, technology and learning in health and physical education. Sport, Education and Society, 22(2), 288-304.

Cho, O., \& Kim, J. (2016). A possibility of school physical education assessment utilizing mobile devices. Korean Journal of Sports Science, 25(1), 905-914.

Cutri, R. M., \& Mena, J. (2020). A critical reconceptualization of faculty readiness for online teaching. Distance Education, 41(3), 361-380.

Eder, R. (2020). The remoteness of remote learning: A policy lesson from COVID-19. Journal of Interdisciplinary Studies in Education, 9(1), 168-171.

Jang, H., \& Lee, J. D. (2017). An analysis of general high school teachers' perceptions on the importance and performance (IPA) of school organizational justice. The Journal of Korean Teacher Education, 34(3), 249-278.

Jang, K. (2017). An exploration on the practices and effects of collaborative teacher inquiry community for the development of novice teachers' PE curriculum enactment competence. $\mathrm{PhD}$ Thesis, Seoul National University, South Korea.

Joo, H., \& Choi, Y. (2019). A study on the education paradigm and a new direction for school physical education in the fourth industrial revolution era. The Korea Journal of Sports Science, 28(1), 755-777.

Joo, H., \& Kim, S. (2018). A study on middle and high school PE teacher's perceptions of technology physical education classes. Journal of Wellness, 13(2), 81-99.

Kang, T. (2013). An analysis of teachers' awareness of Edu-fine School Accounting System aimed at effective school administration. Korean International Accounting Review, 52, 291-314.

Kang, Y. (2019). Analyzing occupational realities and developing occupational standards of Korean physical Education teachers. PhD Thesis, Chung-Ang University, South Korea.

Kim, B. S., \& Lyu, M. J. (2015). Development of application selfdirected learning for physical education in middle and high school. Korean Journal of Sport Pedagogy, 22(1), 89-107.

Kim, C. W. (2014). Problems of physical education classes in elementary schools and ways to vitalize physical education. Journal of Korean Society for the Study of Physical Education, 19(1), 1-14.

Kim, S., Kim, E., Jeon, H., Jung, C., Chong, J., \& Lee, B. (2017). SMART gym class to learn and share easily. Rainbow Books.

Kim, T., Cho, J., \& Lee, B. (2015). A study on the development strategy of smart learning for public education. Journal of Internet Computing and Services, 16(6), 123-131.

Kim, W., \& You, J. (2010). Practical dilemmas and strategies of experienced teachers as curriculum makers. Korean Journal of Sport Pedagogy, 17(4), 39-66.

Leam, J., \& Ahn, S. (2014). A qualitive study on educational usefulness and problems of smartpad-based instruction in elementary school. Journal of the Korean Association, 18(1), 75-87.

Lee, D., Ham, E., \& Ham, S. (2019). Why do teachers have a low sense of efficacy in Korea? The importance of systemwide school autonomy. Korean Journal of Educational Administration, 27(1), 63-81.

Lee, H., \& Jin, Y. (2016). A review of benefits and trends for the three specific and distinct products using technology in physical education. Journal of Korean Association of Physical Education and Sport for Girls and Women, 30(4), 275-289. 
Lee, M. (2016). The qualitative study on difficulties and support of professional adjustment of beginning technology teacher. The Korean Journal of Technology Education, 16(3), 22-45.

Lee, S. H. (2011). Problems of the overly state-initiated system of educational administration in Korea and the search for a new paradigm. Korean Education Inquiry, 29(2), 309-325.

Lee, W. H. (2019). An inquiry into the processes and factors of secondary physical education teachers' occupational identity formation: Toward subject, student, administration. Master's Thesis, Seoul National University, South Korea.

Lee, Y., \& Jun, S. (2014). The effect of organizational justice perception on job satisfaction among secondary physical education teachers. Korean Journal of Sports Science, 23(3), 921-934.

Lee, Y. H., \& Jung, K. I. (2017). The effects of applying smart learning to fun elements and class satisfaction in physical education class in elementary school. The Korean Journal of Elementary Physical Education, 23(1), 69-87.

Lim, Y. T., Lee, M. H., Jin, S., \& Hwang, S. W. (2010). Teacher! it`s rainy! What do we do in P.E. class? Practice of P.E. in the classroom utilizing diverse web-based technologies. Korean Journal of Sport Science, 21(1), 1076-1093.

Martilla, J. A., \& James, J. C. (1977). Importance-performance analysis. Journal of Marketing, 41(1), 77-79.

Matzler, K., Bailom, F., Hinterhuber, H. H., Renzl, B., \& Pichler, J. (2004). The asymmetric relationship between attribute-level performance and overall customer satisfaction: A reconsideration of the importance-performance analysis. Industrial Marketing Management, 33(4), 271-277.

Ministry of Culture, Sports and Tourism. (2017). Announcement of the recruitment of basic local governments to participate in the virtual reality sports room dissemination project for elementary schools to promote sports activities for the physically vulnerable in 2017.

Moon, K. (2017). A study on smart education content development for an integrated elementary physical education that cultivates sport literacy. Master's Thesis, Seoul National University, South Korea.

Noh, K., Ju, S., \& Jung, J. (2011). An exploratory study on concept and realization conditions of smart learning. The Journal of Digital Policy and Management, 9(2), 79-88.

Ohuruogu, B., Ikechukwu, U. J., Mong, E., \& Chinyere, A. E. (2019). Application of information and communication technology (ICT) in administration of physical education and sports. Journal of Education and Practice, 10(24), 1-8.

Park, J., \& Yu, C. (2017). A study on the direction of physical educational based on the changes of school education in the future society. Korean Journal of Sport Pedagogy, 24(2), 1-17.
Park, S., Kim, S., \& Kim, Y. (2018). Current status and development plan of ICT convergence physical education class using virtual reality (VR) sports. Journal of Learner-Centered Curriculum and Instruction, 18(18), 1003-1025.

Putro, B. N., Pratama, H. G., Prasetyo, W., \& Doewes, R. I. (2020). E-learning implementation in physical education department in higher education during COVID-19 pandemic. Information Technology, Education and Society, 17(2), 67-80.

Saaty, T. L. (1980). The analytic hierarchy process. McGraw Hill.

Saaty, T. L. (1987). The analytic hierarchy process: What it is and how it is used. Mathematical Modelling, 9(3-5), 161-176.

Seo, S., Kim, Y., Baek, S., Kim, J., Hong, S., \& Kim, M. (2015). Development of unified platform technology for realistic sports experience of youths. Electronics and Telecommunications Trends, 30(4), 46-53.

Shettar, M. R., Lathiwale, Z. S. M., \& Kulhalli, M. (2021). The role of ICT in higher education in selected places during COVID19. Journal of Research in Social Sciences and Language, 1(1), 42-54.

Song, J., \& Choi, W. (2018). Perception of physical education teachers on national curriculum: Focused on Schwab's six sings of crisis in the field of curriculum. Korean Society for Study of Physical Education, 22(4), 1-14.

Steinberg, C., Zühlke, M., Bindel, T., \& Jenett, F. (2020). Aesthetic education revised: A contribution to mobile learning in physical education. German Journal of Exercise and Sport Research, 50(1), 92-101.

Villalba, A., González-Rivera, M. D., \& Díaz-Pulido, B. (2017). Obstacles perceived by physical education teachers to integrating ICT. Turkish Online Journal of Educational Technology-TOJET, 16(1), 83-92.

You, J., Son, H., \& Jin, Y. (2019). The possibility of technology integration in competency based physical education. The Journal of Educational Studies, 50(3), 131-152.

Zae, S. Z., \& Youn, H. S. (2015). Middle school novice physical education teachers' changes in thinkingin the process of curriculum reconstruction for good teaching. Journal of Research in Curriculum Instruction, 19(2), 259-280.

Publisher's Note Springer Nature remains neutral with regard to jurisdictional claims in published maps and institutional affiliations. 